OPEN ACCESS

Edited by: Juha Salmela, Spinnova Ltd., Finland

Reviewed by: Antti llmari Koponen, VTT Technical Research Centre of Finland Ltd., Finland Zhibao Huo,

Shanghai Jiao Tong University, China

*Correspondence: Mohidus Samad Khan mohid@che.buet.ac.bd

Specialty section: This article was submitted to Chemical Engineering, a section of the journal Frontiers in Chemistry

Received: 30 May 2018 Accepted: 28 September 2018 Published: 17 October 2018

Citation: Islam MN, Ahmed I, Anik MI, Ferdous MS and Khan MS (2018) Developing Paper Based Diagnostic Technique to Detect Uric Acid in

Urine. Front. Chem. 6:496. doi: 10.3389/fchem.2018.00496

\section{Developing Paper Based Diagnostic Technique to Detect Uric Acid in Urine}

\author{
Md. Nazibul Islam, Isteaque Ahmed, Muzahidul Islam Anik, Md. Sakib Ferdous and \\ Mohidus Samad Khan* \\ Department of Chemical Engineering, Bangladesh University of Engineering and Technology, Dhaka, Bangladesh
}

Urinary or serum uric acid concentration is an indicator of chronic kidney condition. An increase in uric acid concentration may indicate renal dysfunction. Reliable instantaneous detection of uric acid without requiring sophisticated laboratory and analytical instrumentation, such as: chromatographic and spectrophotometric methods, would be invaluable for patients with renal complication. This paper reports the early development of a simple, low-cost, instantaneous and user-friendly paper based diagnostic device (PAD) for the qualitative and quantitative detection of uric acid in urine. A colorimetric detection technique was developed based on the intensity of Prussian blue color formation on paper in presence of uric acid; the reaction rate of corresponding chemical reactions on paper surface was also studied. Based on the colorimetric signal produced on paper surface, a calibration curve was developed to detect unknown concentration of uric acid in urine. The effect of temperature on formation of color signal on paper surface was also analyzed. In this study, estimation of urinary uric acid using MATLAB coding on a windows platform was demonstrated as the use of software application and digital diagnostics. This paper-based technique is faster and less expensive compared to traditional detection techniques. The paper-based diagnostic can be integrated with a camera of smart phone, tablet computer or laptop and an image processing application (using windows/android/IOS platform) as a part of digital diagnostics. Therefore, with proper calibration, the paper-based technique can be compatible and economical to the sophisticated detection techniques used to detect urinary uric acid.

Keywords: uric acid, renal dysfunction, paper diagnostics, colorimetric detection, reaction kinetics

\section{INTRODUCTION}

Uric acid is the final byproduct of purine metabolism for human (Heinig and Johnson, 2006; Amir et al., 2011). A change in dietary behavior, such as: an increase in consumption of purine rich foods e.g., meat and seafood, sugar-sweetened beverages, and alcohol, can result in an increase in uric acid levels in urine and blood (Heinig and Johnson, 2006; Lowl et al., 2010; Roddy and Dohert, 2010; Amir et al., 2011; Rho et al., 2011). In addition, an increase in uric acid may indicate defects of uric acid transport in the nephron and renal under-excretion of uric acid (Perez-Ruiz et al., 2002; Heinig and Johnson, 2006). A higher level of serum uric acid (>7 mg/dl for men and $>6.5 \mathrm{mg} / \mathrm{dl}$ for women) or urinary uric acid ( $>700 \mathrm{mg} /$ day) is known as hyperuricemia 
(Perez-Ruiz et al., 2002; Heinig and Johnson, 2006; Siu et al., 2006; Chonchol et al., 2007; Mohandas and Johnson, 2008; Lowl et al., 2010; Amir et al., 2011). Hyperuricemia may disrupt renal function by causing renal arteriolar changes and glomerular damage which may lead to de novo renal disease as well as accelerate existing renal diseases (Perez-Ruiz et al., 2002; Heinig and Johnson, 2006; Siu et al., 2006; Chonchol et al., 2007; Mohandas and Johnson, 2008). Prolonged occurrence (> 3 months) of renal dysfunction can lead to chronic kidney disease (CKD) (Siu et al., 2006; Chonchol et al., 2007; Jha et al., 2013). In 2010, CKD was ranked 18th in the list of the "causes of total number of global deaths," which was ranked 29th back in 1990 (Jha et al., 2013). According to the World Health Organization (WHO), in 2012, an estimated 864,226 deaths (1.5\% of deaths worldwide) were attributed to CKD (Webster et al., 2016). In addition, hyperuricemia is a precursor of gout, and is associated with the development of type 2 diabetes, obesity, Lesch-Nyhan syndrome, and arteriolar hypertension which may lead to cardiovascular disease (Perez-Ruiz et al., 2002; Bos et al., 2006; Heinig and Johnson, 2006; Siu et al., 2006; Chonchol et al., 2007; Dehghan et al., 2008; Mohandas and Johnson, 2008; Lowl et al., 2010; Amir et al., 2011). However, early detection of kidney disease can reduce the risk of kidney failure progression and cardiovascular disease by up to 50\% (Biljak et al., 2015). Since uric acid concentration can be used as a biomarker to monitor renal health (Perez-Ruiz et al., 2002; Chonchol et al., 2007; Mohandas and Johnson, 2008; Lowl et al., 2010), a rapid, reliable, and low cost technique to detect uric acid from human biofluids will be beneficial to patients and physicians.

Existing analytical methods to detect uric acid in biofluids include spectroscopy, chromatography, electrochemistry, membrane and capillary electrophoresis (Gochman and Schmitz, 1971; Kageyama, 1971; Kabasakalian et al., 1973; Inoue et al., 2003; Perelló et al., 2005; Cooper et al., 2006; Arora et al., 2009; Uricase/PAP test, 2009; Bhawna and Pundir, 2010; Rocha and Rocha, 2010; Amir et al., 2011; Sanchez et al., 2011; Sidorova and Grigoriev, 2012; Hamzah et al., 2013; WitkowskaNery et al., 2016). Most conventional spectrophotometric methods for uric acid detection involve colorimetric enzymatic reaction, where. uric acid is oxidized in the presence of uricase and forms allantoin (C4H6N4O3), carbon dioxide and hydrogen peroxide (Gochman and Schmitz, 1971; Kageyama, 1971; Kabasakalian et al., 1973; Uricase/PAP test, 2009; Rocha and Rocha, 2010; Hamzah et al., 2013). In addition, researchers have reported a spectrophotometric method based on the reduction of $\mathrm{Cu}(\mathrm{II})$ ions to $\mathrm{Cu}(\mathrm{I})$ ions in presence of urinary uric acid (Rocha and Rocha, 2010; Sanchez et al., 2011). Amir et al. have reported a flow injection spectrophotometric method based on the reduction of potassium ferricyanide in presence of uric acid to potassium ferrocyanide (Amir et al., 2011). Arora et al. have developed an uricase bound membrane coupled with dissolve oxygen (DO) metric uric acid biosensor (Arora et al., 2009; Bhawna and Pundir, 2010). WitkowskaNery et al. have demonstrated a electrochemical biosensor integrated with platinum electrode, enzyme immobilized bioactive paper channel, buffer filled sponge and pencil drawn pseudo-reference electrode to detect glucose and uric acid (WitkowskaNery et al., 2016). There are other studies, which have reported uric acid detection from biofluids (saliva, serum and urine) using high-performance liquid chromatography (HPLC) technique (Jen et al., 2002; Inoue et al., 2003; Perelló et al., 2005; Cooper et al., 2006). The principles, techniques, types of biofluid samples and detection range of different methods of uric acid detection are enlisted in Table 1. These techniques often require sophisticated equipment and out sourcing of samples to specialized laboratories, which makes these detection techniques expensive and time consuming. Hence, there is a need for instantaneous and low-cost point-of-care detection technique capable for qualitative and quantitative detection of uric acid in human biofluids. Paper based diagnostics, often used for health and environmental purposes, can offer an attractive option for detecting biomarkers such as uric acid from biofluids such as urine, serum, etc. (Khan et al., 2009, 2010c, 2015, 2016, 2018a; Shen et al., 2009; Koh et al., 2016; Zhang et al., 2017).

This article reports the early development of a simple, lowcost and user-friendly paper-based diagnostic device (PAD) to detect uric acid in urine. For the proposed device, ferric chloride and potassium ferricyanide solutions were used as reagents. A color chemistry based on the reaction between ferric chloride, uric acid and potassium ferricyanide was used to develop the paper based diagnostic device. In presence of uric acid in biofluid such as urine, Prussian blue color is formed on the paper surface (Adhikamsetty and Jonnalagadda, 2009). Reaction rate of this reaction mechanism on paper surface was also studied. The color formed on paper surface with respect to uric acid concentration was analyzed using image analysis technique ${ }^{1}$. A calibration curve was developed based on the intensity of color formation on paper surface corresponding to known uric acid concentrations. The effect of temperature on color formation on paper was also analyzed. A MATLAB code was generated to demonstrate uric acid detection using computer/cell phone based applications (windows, android or IOS platform). The proposed technique will provide patients living in remote areas and patients with chronic kidney diseases the ability to assess and report urinary uric acid concentration at low cost and on regular basis. This technique will also facilitate physicians to monitor, diagnose and medicate kidney diseases (Khan et al., 2018b).

\section{REACTION MECHANISM AND KINETICS}

Ferric chloride reacts with potassium ferricyanide in presence of uric acid to form Prussian blue. Paper surface was treated with potassium ferricyanide followed by uric acid sample. Ferric chloride solution was introduced to this treated paper to complete the reaction. The reaction scheme is shown below (Silverman and Gubernick, 1946; Izatt et al., 1970; Hill, 1977; Peters, 2008; Adhikamsetty and Jonnalagadda, 2009):

At first, potassium ferricyanide reacts with uric acid $\left(\mathrm{C}_{5} \mathrm{H}_{4} \mathrm{~N}_{4} \mathrm{O}_{3}\right)$ to form potassium ferrocyanide (Equation 1; Silverman and Gubernick, 1946).

\footnotetext{
${ }^{1}$ Image Processing Toolbox, ${ }^{T M}$, User's Guide. 2017, The MathWorks, Inc.
} 
TABLE 1 | Different detection methods of uric acid from biofluids (Gochman and Schmitz, 1971; Kageyama, 1971; Kabasakalian et al., 1973; Inoue et al., 2003; Perelló

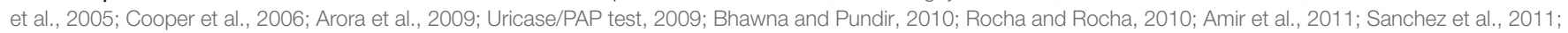
Sidorova and Grigoriev, 2012; Hamzah et al., 2013; WitkowskaNery et al., 2016).

\begin{tabular}{|c|c|c|c|c|}
\hline Principle & Technique & Biofluid sample & $\begin{array}{l}\text { Detection } \\
\text { range (ppm) }\end{array}$ & References \\
\hline $\begin{array}{l}\text { Enzymatic Uricase Method with } \\
\text { 4-Aminodiphenylamine Diazonium } \\
\text { Sulfate }\end{array}$ & Spectrophotometric & Urine & $84-2185$ & Hamzah et al., 2013 \\
\hline $\begin{array}{l}\text { Enzymatic Uricase Method with } \\
\text { 4-Aminoantipyrine } 1 \\
\text { mmol/IPeroxidase }\end{array}$ & Spectrophotometric & Urine, Serum & $0-303$ & Uricase/PAP test, 2009 \\
\hline Enzymatic Uricase-Catalase Method & Spectrophotometric & Urine, Serum & $0-319$ & Kageyama, 1971 \\
\hline $\begin{array}{l}\text { Enzymatic Uricase-Peroxidase } \\
\text { Method coupled with } \\
\text { 3-methyl-2-benzothiazolinone } \\
\text { hydrazone and N,N-dimethylaniline }\end{array}$ & Spectrophotometric & Serum & $0-160$ & Gochman and Schmitz, 1971 \\
\hline $\begin{array}{l}\text { Enzymatic Uricase Method with } \\
\text { Tribromophenol-Aminoantipyrine } \\
\text { Chromogen }\end{array}$ & Spectrophotometric & Serum & $0-319$ & Kabasakalian et al., 1973 \\
\hline $\begin{array}{l}\text { Reduction of Potassium ferricyanide } \\
\text { and formation of Prussian blue }\end{array}$ & Spectrophotometric & Urine, Serum & $0-185$ & $\begin{array}{l}\text { Rocha and Rocha, 2010; Sanchez et al., } \\
2011\end{array}$ \\
\hline $\begin{array}{l}\text { Reduction of } \mathrm{Cu}(\mathrm{II}) \text { ion and } \\
\text { complexation with } \\
4,4^{\prime} \text {-Dicarboxy- } 2,2^{\prime} \text {-Bichinoline (BCA) }\end{array}$ & Spectrophotometric & Urine & $2-17$ & Amir et al., 2011 \\
\hline $\begin{array}{l}\text { Biosensor based on Uricase bound } \\
\text { PVC membrane }\end{array}$ & $\begin{array}{l}\text { Enzyme-membrane } \\
\text { biosensor }\end{array}$ & Serum & $0-100$ & $\begin{array}{l}\text { Arora et al., 2009; Bhawna and Pundir, } \\
2010\end{array}$ \\
\hline capillary zone electrophoresis & Capillary Electrophoresis & Urine & $42-168$ & Sidorova and Grigoriev, 2012 \\
\hline Electrochemical detection & Electrochemical & Proof of concept & $17-200$ & WitkowskaNery et al., 2016 \\
\hline $\begin{array}{l}\text { high-performance liquid } \\
\text { chromatography }\end{array}$ & Chromatographic & Saliva, Serum, Urine & $1-27$ & $\begin{array}{l}\text { Jen et al., 2002; Inoue et al., 2003; Perelló } \\
\text { et al., 2005; Cooper et al., } 2006\end{array}$ \\
\hline
\end{tabular}

$\underset{\text { Uricacid }}{\mathrm{C}_{5} \mathrm{H}_{4} \mathrm{~N}_{4} \mathrm{O}_{3}}+\underset{\mathrm{K}_{3}\left[\mathrm{Fe}(\mathrm{CN})_{6}\right]}{\begin{array}{l}\text { Potassium } \\ \text { ferricyanid }\end{array}} \longrightarrow \begin{aligned} & \mathrm{K}_{4}\left[\mathrm{Fe}(\mathrm{CN})_{6}\right] \\ & \begin{array}{l}\text { Potassium } \\ \text { ferrocyanide }\end{array}\end{aligned}$

Potassium ferrocyanide then reacts with ferric chloride to form Prussian blue (Izatt et al., 1970; Peters, 2008). This reaction takes place in several steps; potassium ferrocyanide reacts with $\mathrm{Fe}^{3+}$ ion to form $\mathrm{HFe}\left[\mathrm{Fe}(\mathrm{CN})_{6}\right]$. There are major and minor paths for $\mathrm{HFe}\left[\mathrm{Fe}(\mathrm{CN})_{6}\right]$ formation (Izatt et al., 1970; Peters, 2008).

Major paths:

$$
\begin{aligned}
& \mathrm{Fe}^{3+}+\left[\mathrm{Fe}(\mathrm{CN})_{6}\right]^{4-} \underset{\mathrm{k}_{-1}}{\stackrel{\mathrm{k}_{1}}{\longrightarrow}} \mathrm{Fe}\left[\mathrm{Fe}(\mathrm{CN})_{6}\right]^{-} \text {(Fast) } \\
& \mathrm{H}^{+}+\mathrm{Fe}\left[\mathrm{Fe}(\mathrm{CN})_{6}\right]^{-} \stackrel{\mathrm{k}_{2}}{\longrightarrow} \mathrm{HFe}\left[\mathrm{Fe}(\mathrm{CN})_{6}\right] \\
& \text { (Slow) Rate limiting }
\end{aligned}
$$

Minor Paths:

$$
\begin{aligned}
& \mathrm{H}^{+}+\left[\mathrm{Fe}(\mathrm{CN})_{6}\right]^{4} \underset{\mathrm{k}_{-3}}{\stackrel{\mathrm{k}_{3}}{\rightleftarrows}} \mathrm{H}\left[\mathrm{Fe}(\mathrm{CN})_{6}\right]^{3-} \\
& \mathrm{Fe}^{3+}+\mathrm{H}\left[\mathrm{Fe}(\mathrm{CN})_{6}\right]^{3-} \stackrel{\mathrm{k}_{4}}{\longrightarrow} \mathrm{HFe}\left[\mathrm{Fe}(\mathrm{CN})_{6}\right](\text { Slow })
\end{aligned}
$$

After the formation of $\mathrm{HFe}\left[\mathrm{Fe}(\mathrm{CN})_{6}\right]$, three molecules of $\mathrm{HFe}\left[\mathrm{Fe}(\mathrm{CN})_{6}\right]$ and one $\mathrm{Fe}^{3+}$ ion assemble to form insoluble Prussian blue (Izatt et al., 1970).

$$
3 \mathrm{HFe}\left[\mathrm{Fe}(\mathrm{CN})_{6}\right]+\mathrm{Fe}^{3+} \underset{\mathrm{k}_{-5}}{\stackrel{\mathrm{k}_{5}}{\longleftarrow}} \underset{\substack{\text { Prussian } \\ \text { blue }}}{\longrightarrow} \mathrm{Fe}_{4}\left[\mathrm{Fe}(\mathrm{CN})_{6}\right]_{3}+3 \mathrm{H}^{+}
$$

Assuming Quasi-equilibrium condition, Equations 2, 4 can be considered very fast reactions, which have high reaction rates, reach equilibrium rapidly and this equilibrium is not affected by neighboring reactions (Hill, 1977). Equation 3 can be regarded as the slowest step which governs the entire process (rate-limiting step).

Thus, the reaction kinetics can be expressed as:

$$
\mathrm{H}^{+}+\mathrm{Fe}\left[\mathrm{Fe}(\mathrm{CN})_{6}\right]^{-} \longrightarrow \mathrm{HFe}\left[\mathrm{Fe}(\mathrm{CN})_{6}\right]
$$

$\begin{array}{llc}t=0 & \text { a } & 0 \\ t=\mathrm{t} & \mathrm{a}-\mathrm{x} & \mathrm{x}\end{array}$

From the graphical representation of the following equations, the reaction order of the above mechanism can be assessed (Bahl et al., 2009):

Zero order: $\quad \mathrm{x}=K \mathrm{t}$

First order $\quad 2.303 \times \log (\mathrm{a}-\mathrm{x})=-\mathrm{Kt}+\mathrm{c}$

Second order $\quad 1 /(\mathrm{a}-\mathrm{x})=K \mathrm{t}+\mathrm{c}$ 

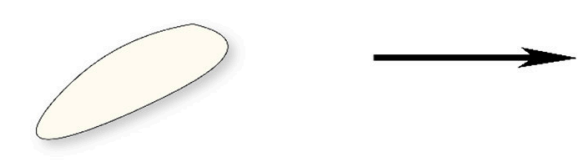

Blank paper
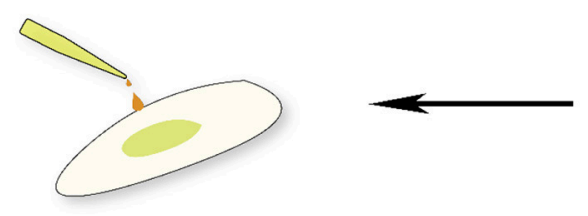

Step 3: Applying Ferric Chloride solution

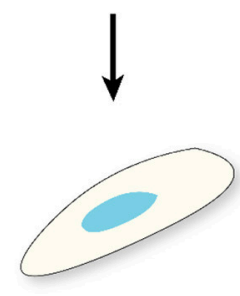

Step 4(a): Color formation on the paper due to reaction
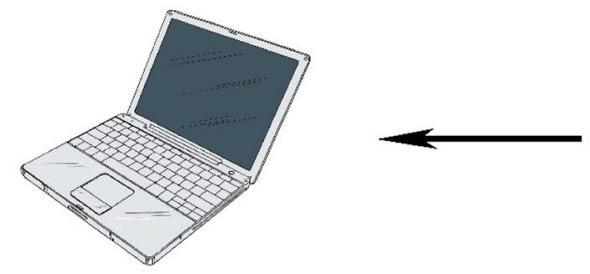

Step 6: Analysis of the video \& images

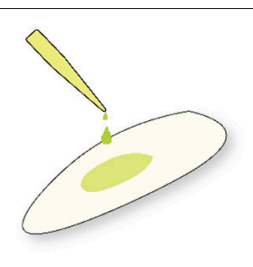

Step 1: Applying ferricyanide solution on paper

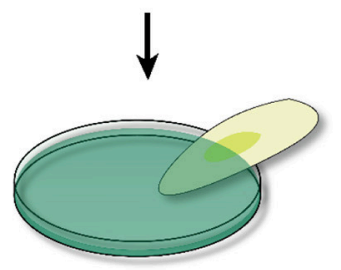

Step 2: Soaking the paper in Urine sample

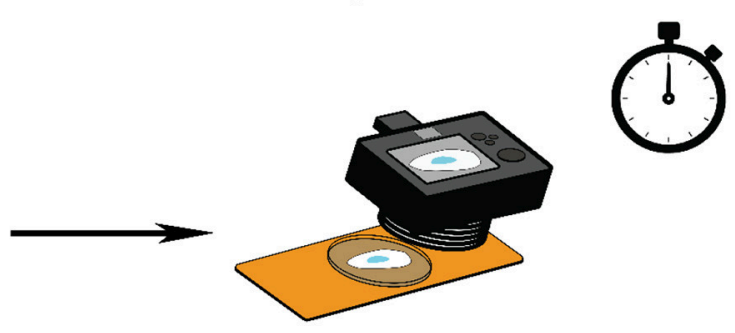

Step 4(b): Recording of the color formation time lapse

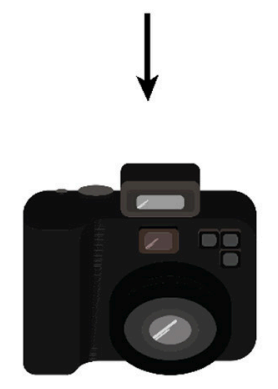

Step 5: Data collection from SD card

FIGURE 1 | Schematic representation of steps involved to develop paper-based technique to detect uric acid and to study reaction kinetics of corresponding chemical reactions on paper surface.

\section{METHODOLOGY}

\section{Materials}

Reagent grade uric acid (Sigma-Aldrich, United States) ${ }^{2}$, potassium ferricyanide (Carl Roth $\mathrm{GmbH}$, Germany) $)^{3}$, ferric

\footnotetext{
${ }^{2}$ Uric acid product specification. Sigma-Aldrich. Editor.

${ }^{3}$ Potassium hexacyanoferrate (III), Specification, C.R. GmbH, Editor.
}

chloride (Loba-chemie, India) ${ }^{4}$, ultra-high purity de-ionized water (18.2M $\Omega . c m$, Purite, United Kingdom), and whatman\# 1 filter paper were used in this study. The artificial urine was prepared in the laboratory (Martinez et al., 2007, 2009). Images used to analyze reaction kinetics were captured using a Sony Alpha 57 DSLR camera (Sony Corp., Japan). The temperature

${ }^{4}$ Ferric chloride (hexahydrate) AR/ACS MSDS CAS: 010025-77-1. (2012). Loba Chemie. 
A

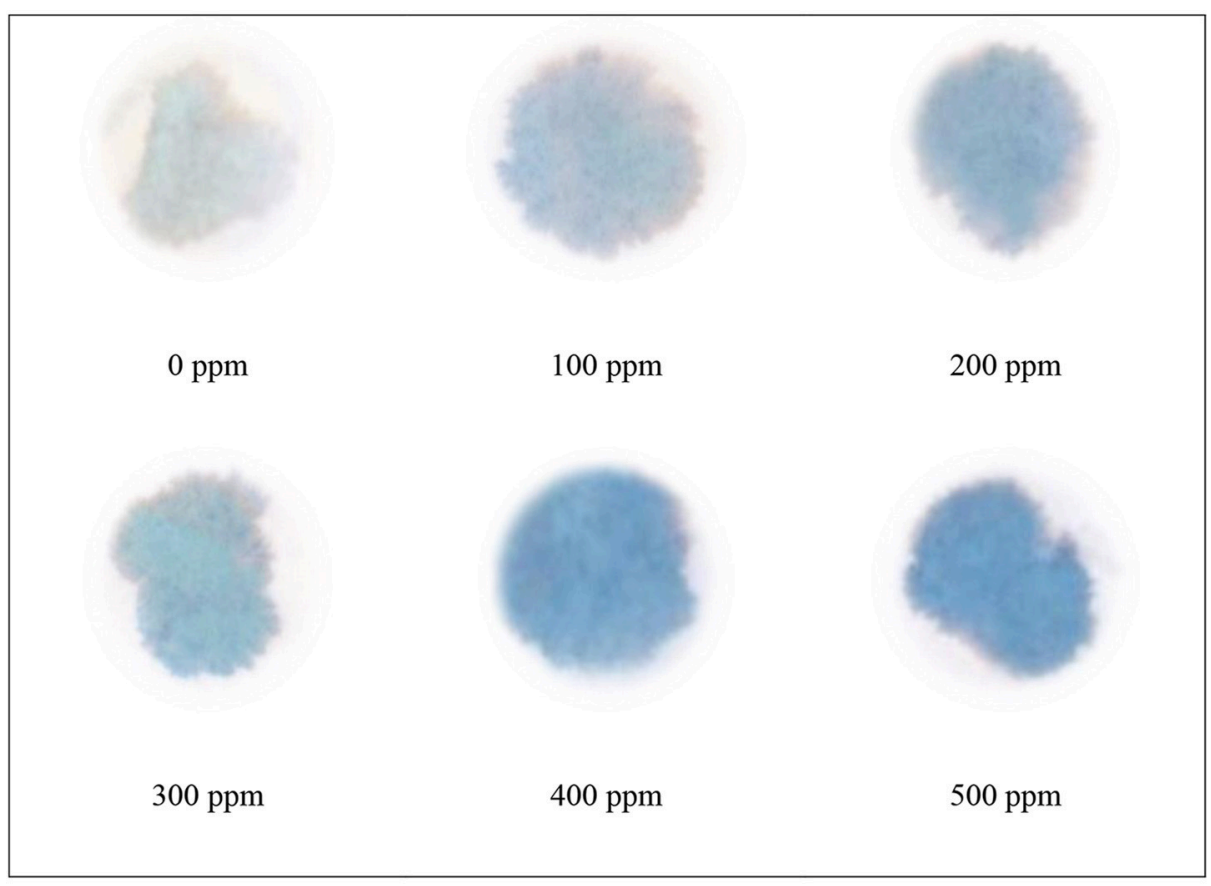

B

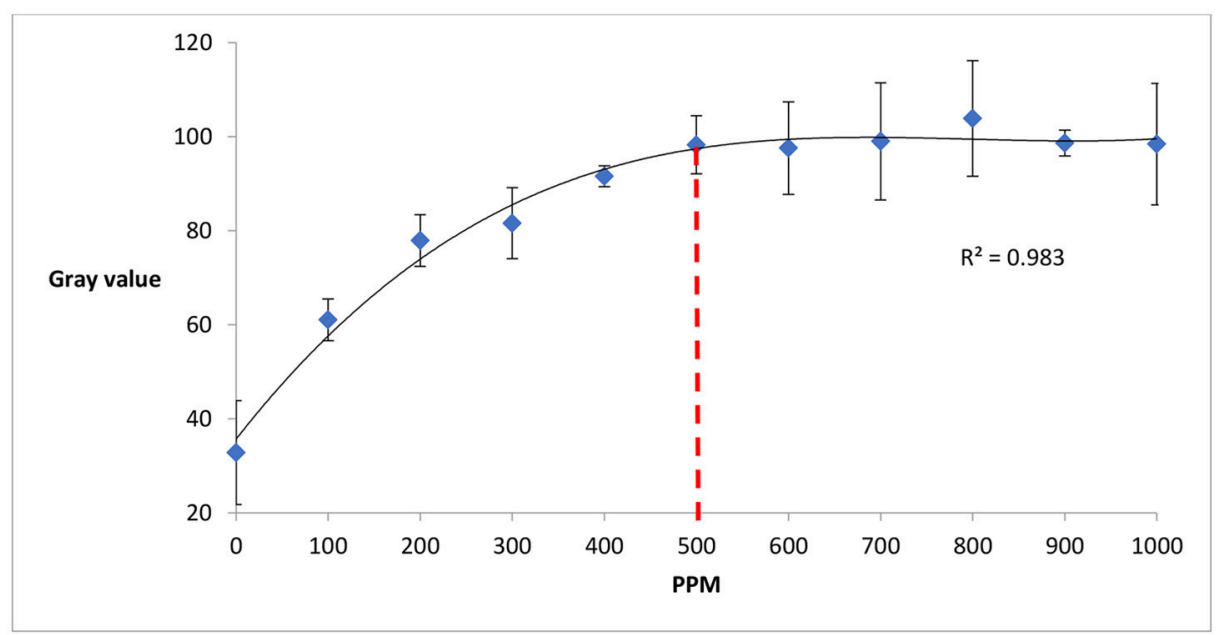

C

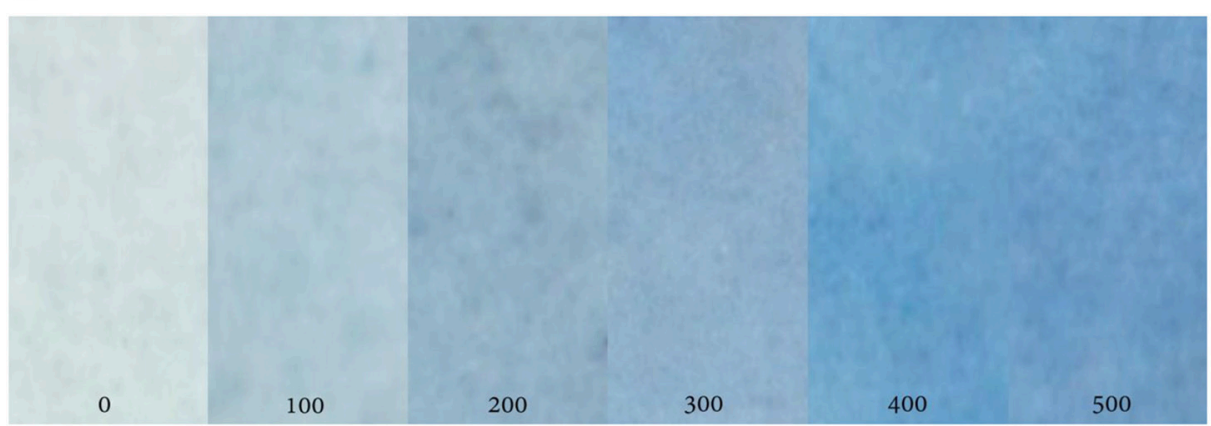

FIGURE 2 | Detection of uric acid concentration in urine using paper diagnostics. (A) Experimental detection of different uric acid concentrations. (B) Change in color intensity (measured in gray value) with respect to the change in uric acid concentration. From the graph it is seen that the color intensity reaches saturation at around 500 ppm of uric acid concentration. (Standard deviation bars for $n=4$ samples) (C). The color gradient shows that higher the concentration, the darker is the color. 

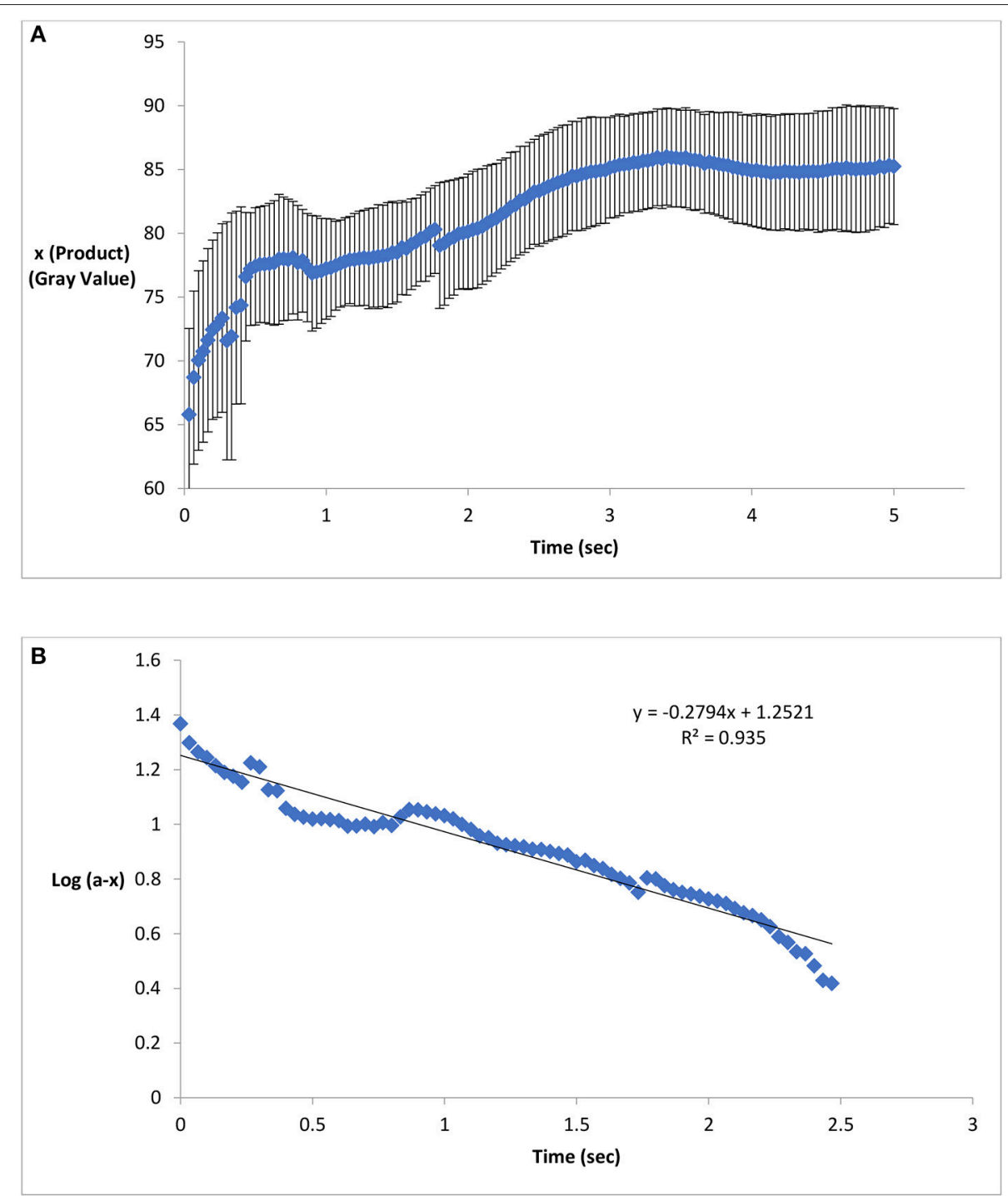

FIGURE 3 | Product formation and reaction kinetics on chemical treated paper surface. (A) Formation of Prussian blue on activated paper as a function of time. The color intensity of the product increased non-linearly as a function of time. (B) A straight line of Log (a-x) vs. time graph conforms first order reaction kinetics and the slope of this straight line indicates the reaction rate (Standard deviation bars for $n=5$ samples).

and humidity were measured using Palmer Hygrometer (Palmer, USA). For calibration curve, the color produced on the paper surface at $25^{\circ} \mathrm{C}$ (room temperature) was measured at $600 \mathrm{dpi}$ using a standard scanner (canon lide 120). The images were analyzed using ImageJ software (ImageJ 1.47t). ImageJ calculates the weighted average gray value within a selected section of an image which can be related to the concentration of uric acid on the activated paper (Khan and Garnier, 2014; Khan et al., 2015). A phoenix RSM $65 \mathrm{H}$ hot plate (Phoenix instruments, Germany) was used to measure relationship between changes in color intensity with respect to temperature.

\section{Method}

Using a micropipette, $30 \mu \mathrm{L}$ potassium ferricyanide solution $(0.01 \mathrm{M})$ was applied on Whatman\#1 filter paper (Diameter:
$2 \mathrm{~cm}$ ). Then, $2 \mathrm{X}$ diluted urine sample was applied on treated paper to make the paper sample saturated. Uric acid in urine reacted with potassium ferricyanide to form potassium ferrocyanide. Finally, $30 \mu \mathrm{L}$ ferric chloride solution $(0.01 \mathrm{M})$ was applied on the treated paper. Prussian blue color was formed on paper surface because of reaction between ferric chloride and potassium ferricyanide (Figure 1). Figure 1 represents schematic diagrams of treating paper surface with different reagents to develop paper diagnostics for uric acid detection. The sensitivity of the test can be improved by increasing the dilution factor of urine sample $(2 \mathrm{X}-5 \mathrm{X})$.

\section{Study of Reaction Order and Kinetics}

To determine the reaction order and kinetics, images were captured using a Sony Alpha 57 DSLR camera on video mode. 


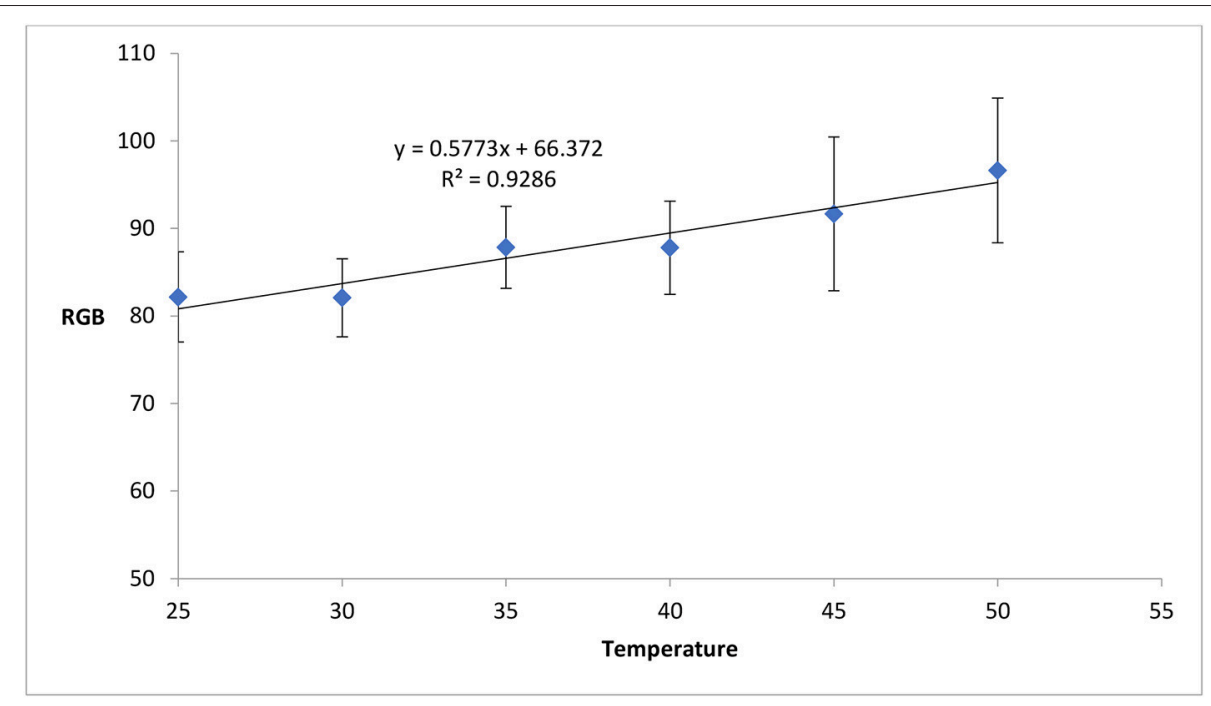

FIGURE 4 | Change in color intensity (measured in gray value) with respect to temperature. The color intensity increases with the increase in temperature. (Standard deviation bars for $n=4$ samples). Paper yellowing effect at high temperature can be probable cause for this increase in color intensity with temperature.

TABLE 2 | Validity test of the paper based uric acid detection technique.

\begin{tabular}{lccc}
\hline No. & $\begin{array}{c}\text { Paper based } \\
\text { technique } \\
(\mathbf{p p m})(\boldsymbol{n}=\mathbf{3})\end{array}$ & $\begin{array}{c}\text { Pathological } \\
\text { trial }(\mathbf{p p m})\end{array}$ & $\begin{array}{c}\text { Published data (ppm) } \\
\text { (Putnam, 1971; Lowl et al., } \\
\text { 2010; Amir et al., 2011) }\end{array}$ \\
\hline 1 & $550 \pm 56$ & 553 & $300-700$ \\
2 & $558 \pm 17$ & 595 & \\
3 & $442 \pm 27$ & 315 & \\
\hline
\end{tabular}

The video clips were transferred to a computer and converted into JPEG files (30 frames per second) using a video to JPEG converter (v. 5.0.99, DVDVideoSoft Ltd. United States). The converted images were analyzed using ImageJ software (ImageJ 1.41t). ImageJ calculates the gray values of RGB (red-greenblue) images. RGB pixels are converted to gray values using the built-in formula (gray $=($ red + green + blue $) / 3)($ Khan and Garnier, 2014; Khan et al., 2015). The RGB color scheme uses a numbering scale ranging from 0 to 255 where the "black" is numbered 0 and the "white" is numbered 255, which means the lower the number, the darker the color. On the other hand, in the CMY (cyan-magenta-yellow) color scheme the "black" is numbered 255 and the "white" is numbered 0 , which means the higher the number the darker the color (Khan and Garnier, 2014; Khan et al., 2015). In the formation of Prussian blue, high concentration of uric acid yields darker color i.e. the darker the color, the higher the uric acid concentration. To correlate the intensity of this color formation with color scheme numbering, the RGB gray values were converted into CMY gray values: CMY $=255-$ RGB (Khan and Garnier, 2014; Khan et al., 2015). Therefore, the gray value results presented in this article are CMY gray values i.e., the darker the color, the higher the gray values and, the higher the concentration of uric acid.

\section{Qualitative and Quantitative Detection of Uric Acid}

To develop a calibration curve for the qualitative and quantitative determination of uric acid in urine, artificial urine (Martinez et al., 2007, 2009) containing different concentrations of uric acid was applied on potassium ferricyanide treated paper samples. Then, ferric chloride was applied on the treated paper samples to form color signals on paper surface. These color signals were scanned and analyzed using standard image processing software (ImageJ 1.41t). The intensity of the color signals produced from the reaction of uric acid and activated paper samples varied according to the concentration of the uric acid in urine solution. Finally, a calibration curve was developed for the qualitative and quantitative detection of uric acid in urine.

\section{Analyzing the Effect of Temperature}

A hot plate (phoenix RSM $65 \mathrm{H}$ hot plate) was used to analyze the effect of temperature on color signal. The temperature of the plate can be set at a desired level. At different set temperatures $\left(25,30,35,40,45\right.$ and $\left.50^{\circ} \mathrm{C}\right)$, potassium ferricyanide treated paper samples (Whatman\#1, Diameter: $2 \mathrm{~cm}$ ) were placed on the plate. To attain equilibrium, the paper samples were kept on the plate for $10 \mathrm{~min}$. Subsequently, steps described in Figure 1 were performed on the paper and the resultant color signal was analyzed.

\section{Computer/Cell Phone Based Application in Health Monitoring}

To demonstrate the concept of windows, android or IOS based application in health monitoring, a MATLAB (Mathworks, r2013a) code was developed for digital analysis of proposed paper based diagnostic kit. Image analysis tool of MATLAB can analyze the color intensity of any image and produce a three-dimensional matrix, which quantifies the color intensity at different points (depending on the resolution of the image, 600 DPI in this case) 


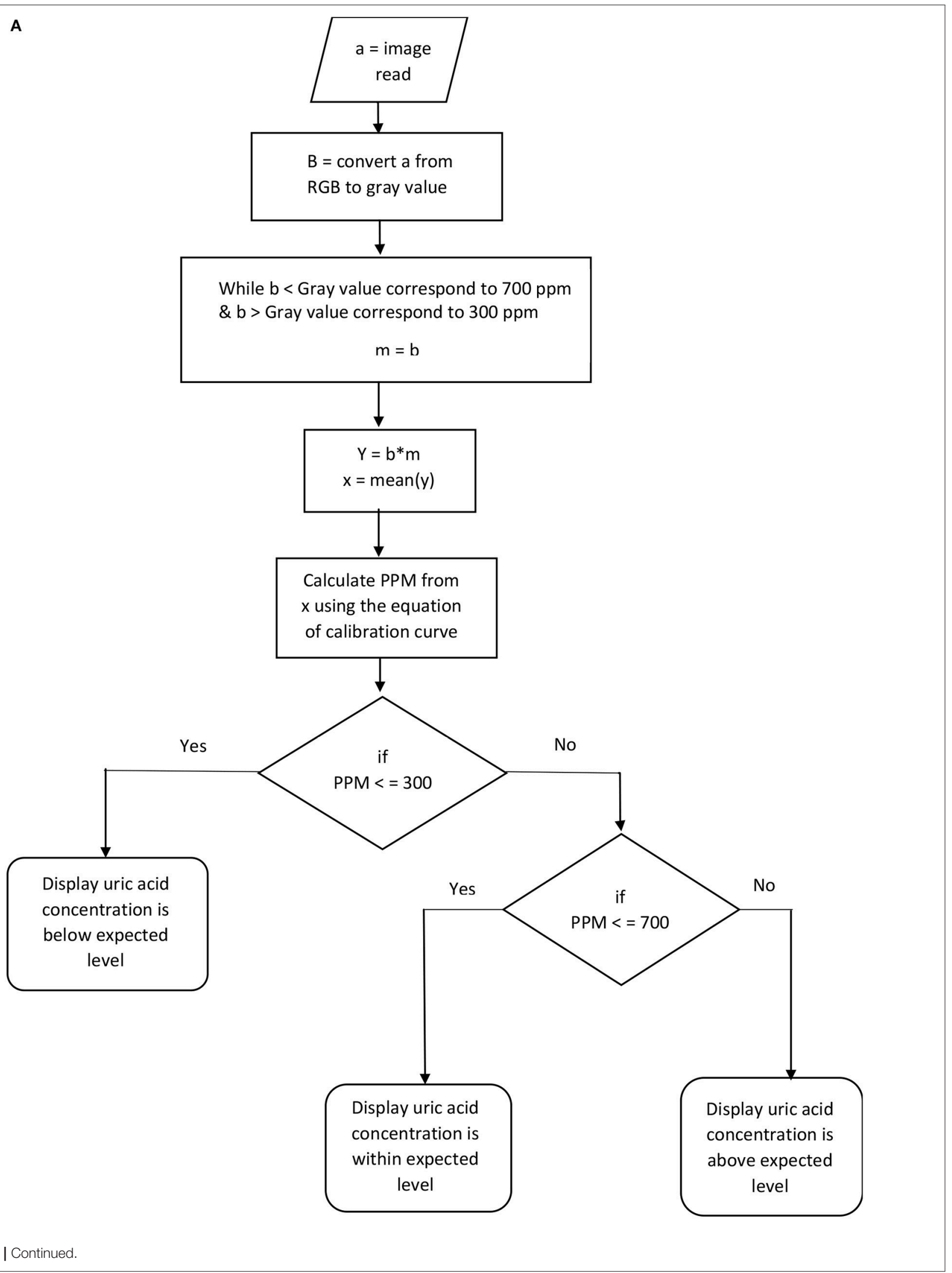

FIGURE 5 | Continued. 
B

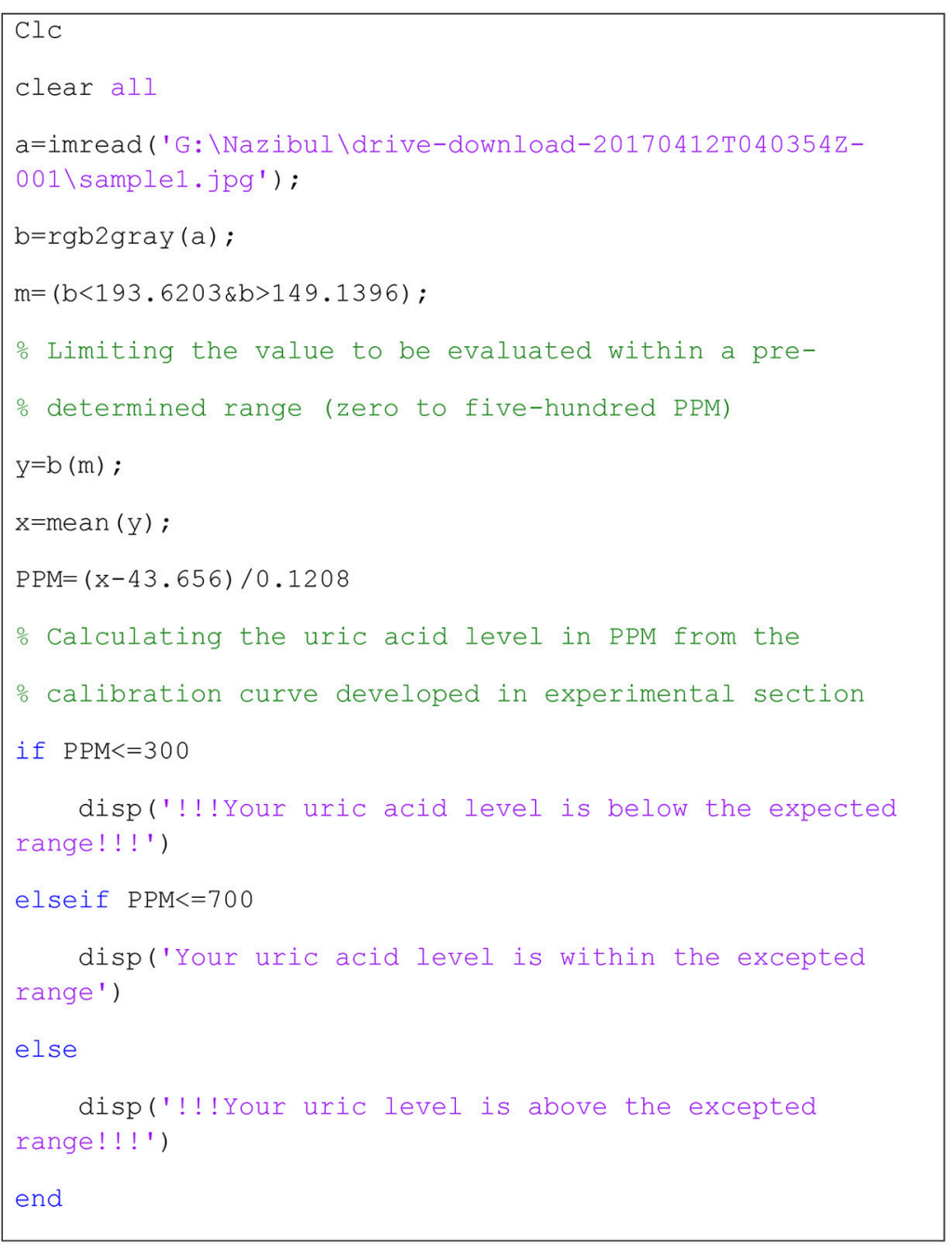

C

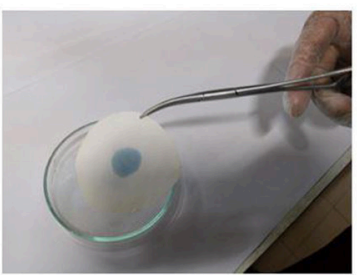

Step 1: Formation of color signal on paper surface

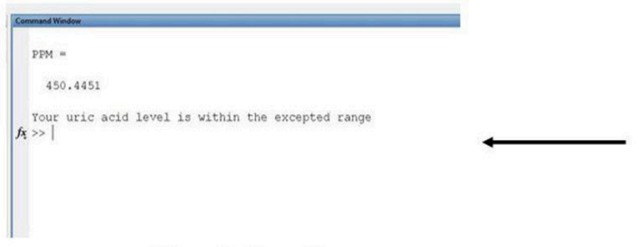

Step 4: Result

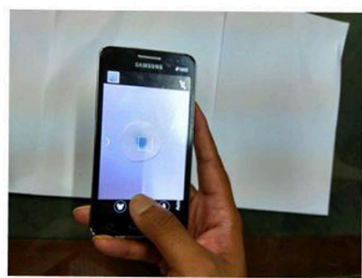

Step 2: Capturing the color signal using a camera unbaled mobile device

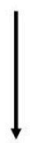

Step 3: Running a MATLAB code to analyze the captured image

FIGURE 5 | Demonstration of application-based detection. (A) Algorithm for the MATLAB code. (B) MATLAB code for color signal analysis. (C) Estimation of urinary uric acid using a mobile device. 
of the image in RGB (Red, green and blue). A code was generated to calculate uric acid concentration from this matrix. This code can be used as a baseline to develop any windows, android or IOS based application integrated with paper diagnostics to detect and report uric acid concentration in urine or any other biofluid.

\section{RESULTS AND DISCUSSION}

\section{Qualitative and Quantitative Detection of Uric Acid in Urine Sample}

To develop paper based diagnostic device (PAD) to detect uric acid in urine, paper samples were treated with potassium ferricyanide $(0.01 \mathrm{M}, 30 \mu \mathrm{L})$, and urine sample was applied on the paper surface. After that, ferric chloride $(0.01 \mathrm{M}, 30 \mu \mathrm{L})$ was added onto the paper samples. Uric acid in urine sample reacted with ferricyanide solution to produce ferrocyanide which then reacted with ferric chloride and produced Prussian blue color signals on the paper surface (Figure 1). The higher the uric acid concentration in urine sample, the stronger the color signals it produced on paper. Figure 2A demonstrates experimental results of qualitative detection of uric acid in urine sample using paper diagnostics.

Color signals formed for different concentrations of uric acid in urine solutions (Figure 2A) were scanned and analyzed using ImageJ software (approximately $100 \mathrm{~mm}^{2}$ at 12.2 pixels $\left./ \mathrm{mm}\right)^{1}$. To understand the change in color intensity with respect to uric acid concentration, corresponding CMY (cyan, magenta and yellow) values of the color signals were plotted against uric acid concentrations (Figure 2B). From Figure 2B, it is seen that the color intensity reaches saturation at around 500 ppm of uric acid concentration. The experimental results produce a color gradient indicating uric acid concentration (Figure 2C): the higher the concentration, the darker the color product formation.

\section{Reaction Rate}

Figure 3 illustrates the reaction kinetics of color formation on paper surface. Figures $\mathbf{3 A}$ indicates the formation of Prussian blue color (x) on activated paper as a function of time. The color intensity of the product increased non-linearly as a function of time. Figure 3B graphically represents $\log (a-x)$ as a function of time; the straight line of $\log (\mathrm{a}-\mathrm{x})$ vs. time graph conforms that the reaction follows first order reaction mechanism. From Figure $3 \mathbf{B}$, the reaction rate constant $(K)$, was calculated as 0.64 $\mathrm{s}^{-1}$. The calculated value is of the same order of magnitude with reported result $\left(0.4-0.47 \mathrm{~s}^{-1} ; 25-30^{\circ} \mathrm{C}\right)$ based on reaction in liquid solution (Adhikamsetty and Jonnalagadda, 2009).

\section{Effect of Temperature}

To determine the effect of temperature on color formation on paper, potassium ferricyanide treated paper samples were kept at different temperatures and concentration of uric acid sample was tested using those treated papers at corresponding temperatures. The color intensity was found to increase with respect to the increase in temperature (Figure 4). An increase in temperature from $25^{\circ}$ to $50^{\circ} \mathrm{C}$ changes the RGB value from 82 to 96 . A probable reason of the increase in color intensity on paper surface could be the paper yellowing effect at high temperature
(Bigourdan and Reilly, 2002; Khan et al., 2010a,b; Karlovits and Gregor-Svetec, 2012). Correction factor of temperature or temperature specific calibration curve can be used to render accurate results.

\section{Laboratory Trial}

The paper diagnostic technique was used to detect unknown uric acid concentration in urine. Twenty-four-hour urine samples were collected from three male subjects aged between 20 and 25 years. The uric acid concentrations of these urine samples were then measured using the proposed paper-based technique. The calibration curve (Figure 2B, 0-500 ppm) was used to quantify uric acid concentrations for corresponding color signals. Pathological laboratory trials were also performed to determine serum uric acid using existing diagnostic technique (Modified Fossati method; Fossati et al., 1980). In this method, $\mathrm{H}_{2} \mathrm{O}_{2}$ produced in enzymatic oxidation of uric acid, reacts with 4-aminoantipyrine (4-AAP) in the presence of $\mathrm{N}, \mathrm{N}$ bis(4-sulfobutyl)-3,5-dimethylaniline, disodium salt (MADB) to produce a blue dye which is then measured using a spectrophotometer (Fossati et al., 1980; Coulter, 2009). The serum uric acid concentrations were then converted into urinary uric acid concentration (Sila-On et al., 1991). Pathological laboratory trial data were compared to corresponding PAD trial data (Table 2). The results were also compared with published data (Putnam, 1971; Lowl et al., 2010; Amir et al., 2011). Table 2 shows that pathological laboratory trial data and PAD trial data are compatible and within acceptable limit (Putnam, 1971; Lowl et al., 2010; Amir et al., 2011); PAD data for patient 3 was higher than that of pathological laboratory data; however, both are within acceptable limit (300-700 ppm).

\section{APPLICATION BASED DETECTION}

The proposed diagnostic technique can be integrated with windows, android or IOS based applications to detect and report uric acid concentration in urine. The color signal produced on the paper, can be analyzed with the help of a camera enabled mobile devices, computers or electronic gadgets. The results can be stored in the device to monitor urinary uric acid trend with time and can be sent to an established medical facility for further analysis. Figure 5A describes the algorithm for the code; Figure 5B illustrates a MATLAB code which can be used as a baseline to develop any mobile application. According to the algorithm, the image is at first inserted into the MATLAB program. MATLAB reads the image in RGB (Red, Green and Blue) format, which is displayed as a 3-dimensional matrix. This $3 \mathrm{D}$ matrix is then converted into a $2 \mathrm{D}$ matrix by converting the RGB image to Gray image (Black and White image). Outliers from this matrix are then sorted and eliminated. The mean value from the resulting matrix is taken for further calculation. Equation developed from the calibration curve is used to convert the color value (mean value) into concentration value as parts per million (ppm) of uric acid. Finally, this value is displayed with a concluding remark. Figure 5C shows the estimation of urinary uric acid using a mobile device. 


\section{CONCLUSION}

This article presents the development of the first-generation point-of-care paper-based detection technique for qualitative and quantitative detection of uric acid in urine. The reaction kinetics of corresponding chemical reactions and effect of temperature on color formation mechanism on paper surface was also analyzed. It was found that the mechanism follows first order reaction kinetics and temperature may affect the colorimetric technique. A calibration curve was developed to measure the uric acid present in urine from color intensity. As a proof of concept, the uric acid content in the urine of adult males was measured using proposed $\mathrm{PAD}$, which were compatible with laboratory trial data and within acceptable limit reported in literature. This technique can also be integrated as a part of digital diagnostics with the help of a camera of smart phone, tablet computer or laptop, and image processing software. Estimation of urinary uric acid using MATLAB coding on a windows platform was demonstrated as the use of software application and digital diagnostics.

The proposed paper diagnostic for uric acid detection in urine and other biofluids is cheap, biocompatible, biodegradable, and can give results in few seconds. Using the proposed technique, patients can regularly (daily or weekly) monitor urinary uric acid level at home. If the urinary uric acid level is frequently found close to or higher than the acceptable limit, the patients can take necessary steps to reduce uric acid level by changing their diets and lifestyle, or by consulting a doctor for further analysis and advice. This technique will also facilitate physicians

\section{REFERENCES}

Adhikamsetty, R. K., and Jonnalagadda, S. B. (2009). Kinetics and mechanism of prussian blue formation. Bull. Chem. Soc. Ethiop. 23, 47-54. doi: 10.4314/bcse.v23i1.21297

Amir, W., Mohammad, Y., Abdul, N., Ghulam, M., and Izhar, H. (2011). Flowinjection spectrophotometric determination of uric acid in urine via prussian blue reaction. Chem. Res. Chinese Univ. 27, 929-933. Available online at: http:// www.cjcu.jlu.edu.cn/hxyj/EN/abstract/abstract13387.shtml

Arora, J., Nandwani, S., Bhambi, M., and Pundir, C. S. (2009). Fabrication of dissolved $\mathrm{O} 2$ metric uric acid biosensor using uricase epoxy resin biocomposite membrane. Analyt. Chim. Acta 647, 195-201. doi: 10.1016/j.aca.2009.06.001

Bahl, A., Bahl, B. S., and Tuli, G. D. (2009). Essentials of Physical Chemistry. Delhi: S. Chand and Company.

Bhawna, and Pundir, C. S. (2010). Fabrication of dissolved O2 metric uric acid biosensor based on uricase bound to PVC membrane. J. Sci. Industr. Res. 69, 695-699. Available online at: http://nopr.niscair.res.in/handle/123456789/ 10111

Bigourdan, J. L., and Reilly, J. M. (2002). "Effects of fluctuating environments on paper materials- stability and practical significance for preservation," in La Conservation à l'ère du Numérique: Actes des Quatrièmes Journées Internationales d'études de l'ARSAG (Paris: Association pour la recherche scientifique sur les arts graphiques), 180-192. Available online at: https://trove. nla.gov.au/work/20678702? selectedversion=NBD40158921

Biljak, V. R., Honović, L., Matica, J., KneŽević, B., and Vojak, S. Š. (2015). Laboratory diagnostics of chronic kidney disease in Croatia: state of the art. Biochemia Medica 25, 73-83. doi: 10.11613/BM.2015.009

Bos, M. J., Koudstaal, P. J., Hofman, A., Witteman, J. C., and Breteler, M. M. (2006). Uric acid is a risk factor for myocardial infarction and stroke: the rotterdam study. Stroke 37, 1503-1507. doi: 10.1161/01.STR.0000221716.55088.d4 and dietitians to monitor and medicate kidney conditions of their patients.

\section{ETHICS STATEMENT}

Research and manuscript are original and unpublished. All authors read and approved the final manuscript. The authors followed the instructions from university medical center and local pathological laboratories while collecting and testing urine samples from volunteers. The volunteers gave signed consent letters as a sign of agreement to provide urine samples to support and validate the study.

\section{AUTHOR CONTRIBUTIONS}

MI carried out a major part of the literature review, experimental studies and drafted the manuscript. IA, MA, and MF carried out literature review and performed laboratory experiments. IA also helped developing MATLAB code. MK conceived the study, supervised the research project and manuscript preparation, and helped to revise and finalize the manuscript. The final manuscript was read and approved by all the authors.

\section{ACKNOWLEDGMENTS}

This research was supported by BCEF Academic Research Fund (date: 19-07-2014), and CASR Research Fund, BUET [DAERS/CASR/R-01/2017/DR-2310(73)]. The research and manuscript are free of conflict to interest.

Chonchol, M., Shlipak, M. G., Katz, R., Sarnak, M. J., Newman, A. B., Siscovick, D. S., et al. (2007). Relationship of uric acid with progression of kidney disease. Am. J. Kidney Dis. 50, 239-247. doi: 10.1053/j.ajkd.2007.05.013

Cooper, N., Khosravan, R., Erdmann, C., Fiene, J., and Lee, J. W. (2006) Quantification of uric acid, xanthine and hypoxanthine in human serum by HPLC for pharmacodynamic studies. J. Chromatogr. B Analyt. Technol. Biomed. Life Sci. 837, 1-10. doi: 10.1016/j.jchromb.2006.02.060

Coulter, B. (2009). "Uric Acid," OSR General Chemistry, ed S. Kraemer Blvd (Brea, CA: Beckman Coulter, Inc.). Available online at: https://www.beckmancoulter. com/wsrportal/techdocs?docname=/cis/BAOSR6x98/01/EN_URIC

Dehghan, A., van Hoek, M., Sijbrands, E. J., Hofman, A., and Witteman, J. C. (2008). High serum uric acid as a novel risk factor for type 2 diabetes. Daibetes Care 31, 361-362. doi: 10.2337/dc07-1276

Fossati, P., Prencipe, L., and Berti, G. (1980). Use of 3,5-dichloro-2hydroxybenzenesulfonic acid/4-aminophenazone chromogenic system in direct enzymic assay of uric acid in serum and urine. Clin. Chem. 26:227.

Gochman, N., and Schmitz, J. M. (1971). Automated determination of uric acid, with use of a uricase-peroxidase system. Clin. Chem. 17, 1154-1159.

Hamzah, H. H., Zain, Z. M., Musa, N. L. W., Lin, Y. C., and Trimbee, E. (2013). Spectrophotometric determination of uric acid in urine based-enzymatic method uricase with 4-aminodiphenylamine diazonium sulfate (Variamine Blue RT Salt). J. Anal. Bioanal. Tech. S7, 1-6. doi: 10.4172/2155-9872.S7-011

Heinig, M., and Johnson, R. J. (2006). Role of uric acid in hypertension, renal disease, and metabolic syndrome. Cleveland Clin. J. Med. 73, 1059-1064. doi: $10.3949 /$ ccjm.73.12.1059

Hill, C. G. Jr. (1977). An Introduction to Chemical Engineering Kinetics and Reactor Design. Hoboken, NJ: John Wiley and Sons.

Inoue, K., Namiki, T., Iwasaki, Y., Yoshimura, Y., and Nakazawa, H. (2003). Determination of uric acid in human saliva by high-performance liquid chromatography with amperometric electrochemical detection. 
J. Chromatogr. B Analyt. Technol. Biomed. Life Sci. 785, 57-63. doi: 10.1016/S1570-0232(02)00850-4

Izatt, R. M., Watt, G. D., Bartholomew, C. H., and Christensen, J. J. (1970). A Calorimetric Study of Prussian Blue and Turnbull's Blue Formation. Inorganic Chem. 9, 2019-2021.

Jen, J. F., Hsiao, S. L., and Liu, K. H. (2002). Simultaneous determination of uric acid and creatinine in urine by an eco-friendly solvent-free high performance liquid chromatographic method. Talanta 58, 711-7. doi: 10.1016/S0039-9140(02)00377-6

Jha, V., Garcia-Garcia, G., Iseki, K., Li, Z., Naicker, S., Plattner, B., et al. (2013). Chronic kidney disease: global dimension and perspectives. Lancet 382, 260-272. doi: 10.1016/S0140-6736(13)60687-X

Kabasakalian, P., Kalliney, S., and Westcott, A. (1973). Determination of uric acid in serum, with use of uricase and a tribromophenol-aminoantipyrine chromogen. Clin. Chem. 19, 522-524.

Kageyama, N. (1971). A direct colorimetric determination of uric acid in serum and urine with uricase-catalase system. Clin. Chim. Acta 31, 421-426. doi: 10.1016/0009-8981(71)90413-X

Karlovits, M., and Gregor-Svetec, D. (2012). Durability of cellulose and synthetic papers exposed to various methods of accelerated ageing. Acta Polytechnica Hungarica 9, 81-100. Available online at: http://www.uni-obuda.hu/journal/ Issue 38.htm

Khan, M. S., and Garnier, G. (2014). "Novel Image Analysis Technique to Measure Enzymatic Activity and Stability on Paper Surfaces, "in Advances in Image Analysis Research, ed R. M. Echon (New York, NY: Nova Publishers), 217-238.

Khan, M. S., Haniffa, S. B., Slater, A., and Garnier, G. (2010a). Effect of polymers on the retention and aging of enzymatic bioactive papers. Colloids Surfaces $B$ 79, 88-96. doi: 10.1016/j.colsurfb.2010.03.034

Khan, M. S., Islam, M. N., Ahmed, I., Anik, M. I., and Ferdous, M. S. (2018b). LowCost Paper Diagnostics for the Qualitative and Quantitative Detection of Uric Acid in Urine and other Biofluids. US Provisional Patent No. 62672580 (May 17, 2018); BD Provisional Patent Application No. P/BD/2018/000147 (June 7, 2018).

Khan, M. S., Islam, M. N., and Mursalat, M. (2018a). Low-Cost Paper Diagnostics for the Qualitative and Quantitative Detection of Formaldehyde (Formalin, Primary Aldehyde) in Food, Water and other Biofluids. Bangladesh Patent No. 1006040, Dhaka.

Khan, M. S., Li, X., Shen, W., and Garnier, G. (2010b). Thermal stability of bioactive enzymatic papers. Colloids Surf B Biointerfaces 75, 239-246. doi: 10.1016/j.colsurfb.2009.08.042

Khan, M. S., Li, X., Thuas, G., Shen, W., and Garnier, G. (2009). Testing Device for Identifying Antigens and Antibodies in Biofluids. PCT/AU2010/001255, US20120322086 A1, CN102576017A, EP2480885A1, EP2480885A4, WO2011035385A1.

Khan, M. S., Pande, T., and Van de Ven, T. G. (2015). Qualitative and quantitative detection of T7 bacteriophages using paper based sandwich ELISA. Colloids Surfaces 132, 264-270. doi: 10.1016/j.colsurfb.2015.05.028

Khan, M. S., Thouas, G., Shen, W., Whyte, G., and Garnier, G. (2010c). Paper diagnostic for instantaneous blood typing. Analyt. Chem. 82, 4158-4164. doi: $10.1021 /$ ac100341n

Khan, Y., Ostfeld, A. E., Lochner, C. M., Pierre, A., and Arias, A. C. (2016). Monitoring of vital signs with flexible and wearable medical devices. Adv. Mater. 28, 4373-4395. doi: 10.1002/adma.201504366

Koh, A., Kang, D., Xue, Y., Lee, S., Pielak, R. M., Kim, J., et al. (2016). A soft, wearable microfluidic device for the capture, storage, and colorimetric sensing of sweat. Sci. Transl. Med. 8:366ra165. doi: 10.1126/scitranslmed.aaf2593

Lowl, S. Y., Loganathan, A., Sivasangaran, S., and Samy, A. L. (2010). "Association Between Urine Uric Acid Levels and Quality of Life in Academicians and Nonacademicians in UTA\& Kampar," in Intemational Federation for Medical and Biological Engineering Proceedings, eds F. Ibrahim, J. Usman, M. S. Mohktar, and M. Y. Ahmad (Putrajaya: Springer Nature). Available online at: https://link. springer.com/book/10.1007/978-981-10-0266-3

Martinez, A. W., Phillips, S. T., Butte MJ, and Whitesides, G. M. (2009). Simple telemedicine for developing regions: camera phones and paper-based microfluidic devices for real-time, off-site diagnosis. Anal. Chem. 8, 3699-3707. doi: $10.1021 /$ ac 800112 r
Martinez, A. W., Phillips, S. T., Butte M. J., and Whitesides, G. M. (2007). Patterned paper as a platform for inexpensive, low-volume, portable bioassays. Angew. Chem. Int. Ed. Engl. 46, 1318-1320. doi: 10.1002/anie.200603817

Mohandas, R., and Johnson, R. J. (2008). Uric acid levels increase risk for new-onset kidney disease. J. Am. Soc. Nephrol. 19, 2251-2253. doi: 10.1681/ASN.2008091012

Perelló, J., Sanchis, P., and Grases, F. (2005). Determination of uric acid in urine, saliva and calcium oxalate renal calculi by high-performance liquid chromatography/mass spectrometry. J. Chromatogr. B Analyt. Technol. Biomed. Life Sci. 824, 175-180. doi: 10.1016/j.jchromb.2005.07.024

Perez-Ruiz, F., Calabozo, M., Erauskin, G. G., Ruibal, A., and Herrero-Beites, A. M. (2002). Renal underexcretion of uric acid is present in patients with apparent high urinary uric acid output. Arthritis Rheumat. 47, 610-613. doi: 10.1002 /art.10792

Peters, J. (2008). Prussian Blue and Cyanotype Printing, Ellensburg, WA: Central Washington University.

Putnam, D. F. (1971). Composition and Concentrative Properties of Human Urine. Washington, DC: NASA.

Rho, Y. H., Zhu, Y., and Choi, H. K. (2011). The epidemiology of uric acid and fructose. Semin. Nephrol. 31, 410-419. doi: 10.1016/j.semnephrol.2011.08.004

Rocha, D. L., and Rocha, F. R. P. (2010). A flow-based procedure with solenoid micro-pumps for the spectrophotometric determination of uric acid in urine. Microchem. J. 94, 53-59. doi: 10.1016/j.microc.2009.08.010

Roddy, E., and Dohert, M. (2010). Epidemiology of gout. Arthritis Res. Ther. 12:223. doi: $10.1186 /$ ar3199

Sanchez, M. A., Rocha, D. L., Melchert, W. R., and Rocha, F. R. P. (2011). A multicommuted flow system for dissolution studies of Captopril in pharmaceutical preparations. J. Brazil. Chem. Soc. 22, 811-1004. doi: 10.1590/S0103-50532011000500002

Shen, J., Tian, W., X., Li, Khan, M. S., and Garnier, G. (2009). Method of Fabricating Microfluidic Systems. PCT/AU2009/000889, US20120009662, CN102119056A, EP2300165A1, WO2010003188A1 2014.

Sidorova, A. A., and Grigoriev, A. V. (2012). Determination of diagnostical markers of urolithiasis by capillary electrophoresis. J. Analyt. Chem. 67, 478-485. doi: 10.1134/S1061934812050115

Sila-On, A., Pavaro, U., and Nuchpramool, W. (1991). Serum and urinary uric acid levels in healthy subjects and in patients with urolithiasis. J. Med. Assoc. Thai. $74,352-357$.

Silverman, H., and Gubernick, I. (1946). Colorimetric determination of uric acid woth alkaline ferricyanide. J Biol Chem. 167, 363-368.

Siu, Y. P., Leung, K. T., Tong, M. K., and Kwan, T. H. (2006). Use of allopurinol in slowing the progression of renal disease through its ability to lower serum uric acid level. Am. J. Kidney Dis. 47, 51-59. doi: 10.1053/j.ajkd.2005.10.006

Uricase/PAP test (2009). Reagent Kit for the Quantitative Determination of Uric Acid Concentration in Serum and Urine. Enzymatic colorimetric method. Uricase /PAP test. CliniChem: H-1117 Budapest, Budafoki street 111-113.

Webster, A. C., Nagler, E. V., Morton, R. L., and Masson, P. (2016). Chronic Kidney Disease. Lancet 389, 1238-1252. doi: 10.1016/S0140-6736(16)32064-5

WitkowskaNery, E., Santhiago, M., and Kubota, L. T. (2016). Flow in a paper-based bioactive channel - study on electrochemical detection of glucose and uric acid. Electroanalysis 28, 2245-2252. doi: 10.1002/elan.201600210

Zhang, H., Qiu, X., Zou, Y., Ye, Y., Qi, C., Zou, L., et al. (2017). A dye-assisted paper-based point-of-care assay for fast and reliable blood grouping. Sci. Transl. Med. 9, 1-11. doi: 10.1126/scitranslmed.aaf9209

Conflict of Interest Statement: The authors declare that the research was conducted in the absence of any commercial or financial relationships that could be construed as a potential conflict of interest.

Copyright (C) 2018 Islam, Ahmed, Anik, Ferdous and Khan. This is an open-access article distributed under the terms of the Creative Commons Attribution License (CC $B Y)$. The use, distribution or reproduction in other forums is permitted, provided the original author(s) and the copyright owner(s) are credited and that the original publication in this journal is cited, in accordance with accepted academic practice. No use, distribution or reproduction is permitted which does not comply with these terms. 